\title{
Design of a hydrokinetic turbine
}

\author{
E. Chica ${ }^{1}$, F. Pérez ${ }^{1}$, A. Rubio-Clemente ${ }^{2} \&$ S. Agudelo ${ }^{1}$ \\ ${ }^{1}$ Department of Mechanical Engineering, Faculty of Engineering, \\ University of Antioquia, Colombia \\ ${ }^{2}$ Grupo de Diagnóstico y Control de la Contaminación (GDCON), \\ Faculty of Engineering, University of Antioquia, Colombia
}

\begin{abstract}
Hydrokinetic turbine power production depends on the interaction between the rotor and water. Therefore, an optimum geometry of the rotor must be designed and constructed to capture the maximum water energy and convert it into a usable energy. The steps involved in the design and numerical simulation of a small horizontal axis hydrokinetic turbine rotor are presented based on the same incompressible flow techniques used for designing wind turbines. Three blades of a $1 \mathrm{Hp}(746 \mathrm{~W})$ prototype hydrokinetic turbine were designed for a water velocity of $1.5 \mathrm{~m} / \mathrm{s}$ with a tip speed ratio of 6.325 , an angle of attack of $5^{\circ}$ and $0^{\circ}$ as the pitch angle; in order to obtain the maximum power coefficient of the turbine. This coefficient was 0.4382, near the Betz limit. S822 airfoil was used to generate the coordinates of the blade. CFD simulation was carried out using Ansys CFX to estimate the performance of the blade design. Furthermore, FEM was successfully used for stress calculations on turbine blades under the influence of centrifugal and hydrodynamic loading.

The designed hydrokinetic turbine can be used for pico hydro generation in rural communities non-connected to electricity services through the national interconnected electric system, due to its simple structure, and low cost of initial investment. Additionally, it can be locally manufactured, the environmental impact is negligible, since large dams are not involved, and the schemes can be managed and maintained by the consumer.

Keywords: horizontal axis hydrokinetic turbine, CFD, tip speed ratio, power coefficient.
\end{abstract}




\section{Introduction}

Hydrokinetic energy refers to the energy generated from the moving water of the currents in oceans, tidal, rivers and artificial water channels. Several technologies have been developed to extract this energy, such as horizontal axis hydrokinetic turbines [1]. However, these turbines are still in a developmental phase and have not been fully commercialized yet, due to their reliability and low power density. Horizontal axis turbines have some beneficial features which make them more suitable than vertical axis turbines since they are easier self-starting, have less torque fluctuation, higher efficiency and larger speed operation.

The performance of the hydro turbines depends on the rotor, shaft, gear box, and the generator characteristics. The blade or the rotor, which convert kinetic energy of the wind or water current into mechanical energy, is the most important component of a turbine system. This consists of the hub and several blades. The turbine blades are conventionally bolted to the hub. The design of the rotor is considered to be a primary challenge from both hydrodynamic and economic standpoint. The performance of the rotor is a function of the number of blades, tip speed ratio, type of airfoil, power coefficient, blades pitch, chord length and twist and distribution along the blade span [2].

This article focuses on the description of the steps involved in the design and numerical simulation of a small horizontal axis hydrokinetic turbine rotor used, specifically, for generating electrical power for off-grid remote communities in developing countries.

\section{Rotor design of a horizontal axis hydrokinetic turbine}

Hydrokinetic turbines operate under the same principles as wind turbines and share similar design philosophies. Their design starts from the turbine rotor sizing. It is often preferable to have an effective rotor but not a too large one, as the cost increases with the rotor size. The turbine output power $(P)$ in horizontal axis hydrokinetic turbines (eqn. (1)), like in wind turbines is a function of the fluid density $(\rho)$, area swept by the rotor blade $\left(A=\pi R^{2}\right.$, where $R$ is the blade radius or tip radius), the current water velocity $\left(V_{1}\right)$, the power coefficient $\left(C_{p}\right)$ and the drive train efficiency (generator, gearing, etc.) $(\eta)$, which is assumed to be equal to $70 \%$, a typical and conservative value for a small turbine for electric generation $[1,3]$.

$$
P=\frac{1}{2} \rho A V_{1}^{3} C_{p} \eta
$$

The theoretical limit of $C_{p}$, deduced by Bezt, is 0.593 . However, this value has been reported in extensive literature for horizontal axis wind turbines as a nonlinear function of the tip speed ratio $(\lambda)$ and the pitch angle of the turbine $(\theta)$, as represented in eqn. (2) [4]:

$$
C_{p}(\lambda, \theta)=0.22\left(\frac{116}{\lambda_{i}}-0.4 \theta-5\right) e^{\frac{-12.5}{\lambda_{i}}}
$$




$$
\begin{gathered}
\frac{1}{\lambda_{i}}=\frac{1}{\lambda+0.08 \theta}-\frac{0.035}{\theta^{3}+1} \\
\lambda=\frac{R \omega}{V_{1}}
\end{gathered}
$$

The tip speed ratio is defined as the tangential velocity ratio at the tip of the blade to the free steam flow velocity, where $\omega$ is the rotational speed of the hydrokinetic turbine rotor.

With the function defined in eqn. (2), it is possible to evaluate the $C_{p}$ response at different values of the tip speed ratio and pitch angle. This leads to the $C_{p}(\lambda, \theta)$ versus $\lambda$ characteristics for various values of $\theta$, as depicted in fig. 1 .

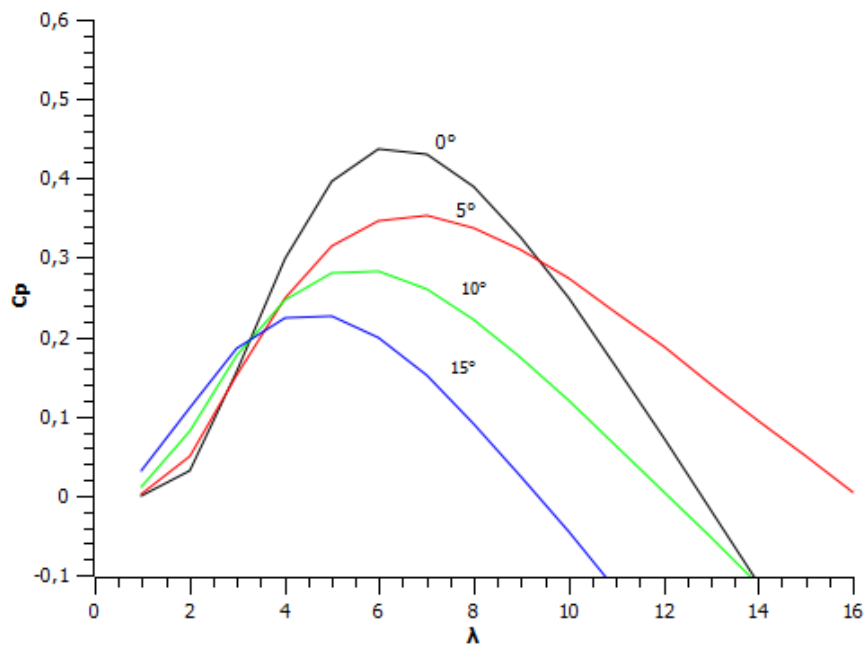

Figure 1: $C_{p}$ as a function of the tip speed ratio $(\lambda)$ with pitch angle $(\theta)$ as parameters.

Fig. 1 shows that for every $\theta$, there is a $\lambda$ yielding the maximum $C_{p}$ and, hence, the maximum efficiency. Note that in fig. $1, C_{p}$ has a maximum of 0.4382 when $\theta$ is equal to 0 and $\lambda$ is 6.325 .

Assuming that the turbine output power $(P)$ is $746 \mathrm{~W}$, the water current velocity is $1.5 \mathrm{~m} / \mathrm{s}, C_{p}$ is $0.4382, \eta$ is $70 \%$ and $\rho$ is $997 \mathrm{~kg} / \mathrm{m}^{3}$ (at $25^{\circ} \mathrm{C}$ ), the radius and, concomitantly, the length of the turbine blades can be calculated using eqn. (1). The length of the blade required is equal to $0.678 \mathrm{~m}$. For simplicity, a blade length of $0.68 \mathrm{~m}$ was used.

Subsequently, given the rotor design parameters (e.g., rotor diameter, tip speed, aerofoil and water current velocity, among others), the main task of the blade design is to determine the chord and twist distributions along the span of the blade. The S series designed by National Renewable Energy laboratory (NREL) in USA, specifically the S822 was used in this work for calculating the coordinates of the 
airfoils because of its resistance to fouling, since it is less sensitive to dirt than the conventional NACA sections. Additionally, it has a reduced roughness sensitivity for improving energy capture under dirty blade conditions. On the other hand, the increased section thickness of the root and tip airfoils allows the blade to have reduced weight, low cost, increased stiffness and improved fatigue resistance. The coordinates of the aerofoil are normally given as a function of the chord length $(C)$ in the form of $x / C, y / C$ and represent the profile (shape and thickness) of the blade.

$C$ can be obtained by equaling the torque on the rotor determined from the momentum theory with the torque obtained from the blade element theory, considering the drag different of zero. $C$ can be worked out using eqn. (5) and the twist angle $(\beta)$ at any point along the blade can be found using eqn. (6). Both equations depend on $\phi$ (angle of the relative water current to the plane of rotation), as shown in fig. 2, which can be obtained from eqn. (7).

$$
\begin{gathered}
C=\frac{\operatorname{8ár}_{r} \pi \operatorname{Sin}^{2} \phi}{\left(C_{L} \operatorname{Sin} \phi-C_{D} \operatorname{Cos} \phi\right) B(1-a)} \\
\beta=\phi-\alpha \\
\operatorname{Tan} \phi=\frac{(1-a)}{\lambda_{r}(1+a)}
\end{gathered}
$$

where $B$ is the number of blades; $\alpha$, the angle of attack; and $\lambda_{r}$, the local tip speed ratio calculated using eqn. (8).

$$
\lambda_{r}=\frac{\omega r}{V_{1}}=\lambda \frac{r}{R}
$$

The term $a$ is the axial induction factor. It is defined as the fractional decrease in water speed between the free stream flow and the rotor plane. The momentum theory is valid only for $a \leq 0.5$. On the other hand, the term $a$ is the angular induction factor. It is similarly defined as the fractional increase in angular velocity due to the increased angular velocity at the blades from the conservation of momentum. $a$ and $a$ are related to the angle of relative water flow by eqn. (7) [5].

From fig. 2 the relative water velocity $\left(V_{R e l}\right)$ can be expressed as a function of $V_{1}, a$ and $\theta$, as indicated in eqn. (9):

$$
V_{\text {Rel }}=\frac{V_{1}(1-a)}{\operatorname{Sin} \phi}
$$

Additionally, the blade element momentum theory is very useful to calculate several types of load on the water turbine blade, like drag and lift force. These forces can be resolved into a normal force $\left(d F_{N}\right)$ to the plane of rotation (this contributes to thrust) eqn. (10) and a tangential force $\left(d F_{T}\right)$ to the circle swept by 


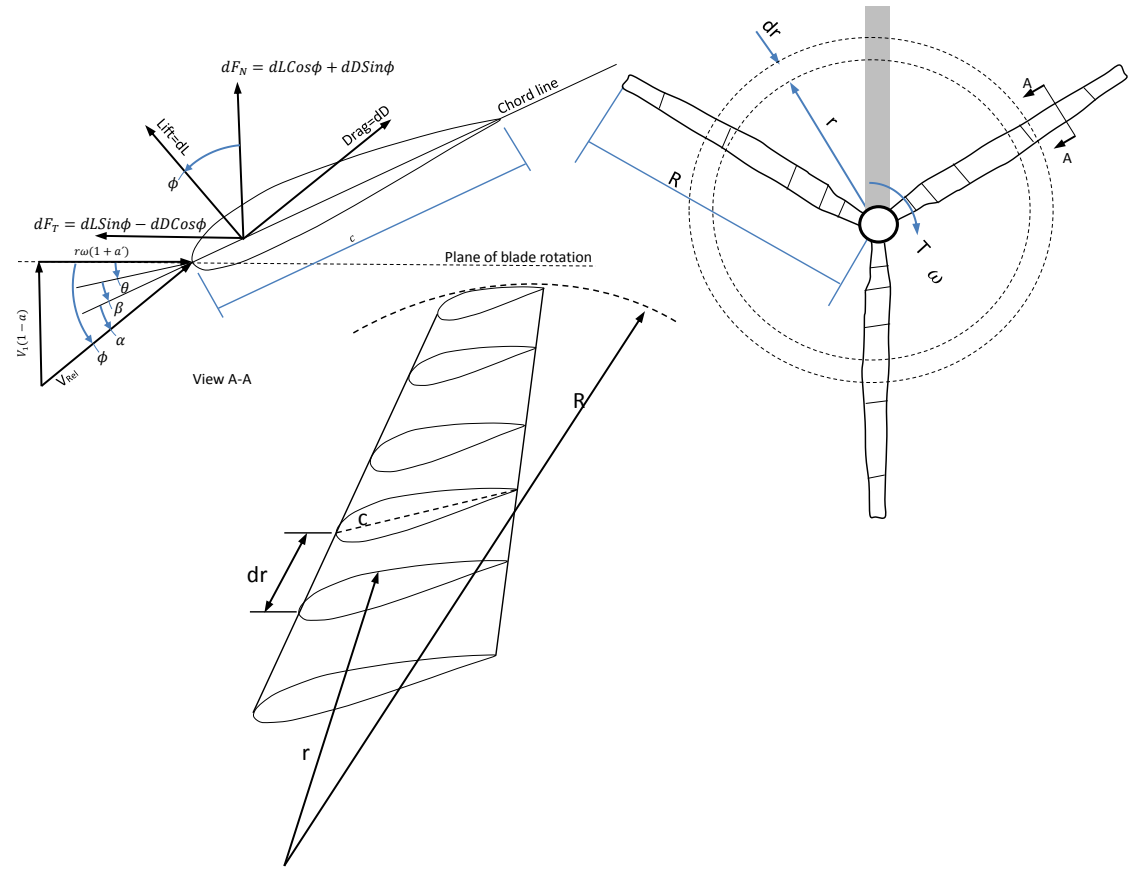

Figure 2: Blade element model.

the rotor eqn. (11) [5].

$$
\begin{aligned}
& d F_{N}=d L \operatorname{Cos} \phi+d D \operatorname{Sin} \phi=\frac{1}{2}\left(C_{L} \operatorname{Cos} \phi+C_{D} \operatorname{Sin} \phi\right) \rho V_{R e l}^{2} C d r \\
& d F_{T}=d L \operatorname{Sin} \phi-d D \operatorname{Cos} \phi=\frac{1}{2}\left(C_{L} \operatorname{Sin} \phi-C_{D} \operatorname{Cos} \phi\right) \rho V_{R e l}^{2} C d r
\end{aligned}
$$

$C p$ representing the fraction of the extracted power by the rotor can be expressed in terms of axial induction factor (eqn. (12)):

$$
C_{p}=\frac{4 a(1-a)^{2}}{\eta}
$$

The maximum $C_{p}$, equal to 0.593 , was determined by taking the derivative of eqn. (12) with respect to $a$, and setting it equal to zero, yielding $a=1 / 3[5,6]$.

Before using eqn. (5), $B, C_{L}, C_{D}, a, a$ and $\phi$ must be determined. In this work $B$ was equal to three $(B=3)$. The reasons were mainly for higher efficiency and smoother output torque compared to two-bladed turbines. The lift and drag coefficients can be obtained from wind tunnel test data for the type of the used airfoil. The values of $C_{L}(0.8)$ and $C_{D}(0.009)$ were used [6]. $\alpha$, a variable in eqn. (6) can also be found from test data, which in this case was $5^{\circ}$. The value of $a$ was determined from eqn. (12) for a $C_{p}$ equal to 0.4382 and $\eta$ equal to $70 \%$. 
In this case, $a$ is 0.15254 , and $\phi$ can be worked out using eqn. (7), but $\lambda_{r}$ must be determined first using eqn. (8).

Once $B, C_{L}, C_{D}, a, a$ and $\phi$ have been found, $C$ and $\beta$ can be calculated for any value of $r$ along the blade. In order to simplify, the whole blade length $(0.68 \mathrm{~m})$ was divided into 10 equal segments, giving each section separated by a distance of $0.068 \mathrm{~m}$. The sections were represented by $r_{1}$ to $r_{10}$, where $r_{1}$ was the section nearest to the root and $r_{10}$, the tip of the blade. An Excel spreadsheet shown in Table 1 was used to obtain the values of $C$ and $\beta$ for each section. Notice that the value of $C$ increases from the tip towards the root. $\beta$ was larger near the root and smaller at the tip (where local speeds are lower and higher, respectively). The conditions of the design produced an angular velocity equal to $133.23 \mathrm{rpm}$.

Table 1: Excel spreadsheet for determining the section chord length and twist angle.

\begin{tabular}{|c|c|c|c|c|c|c|c|}
\hline \multicolumn{8}{|c|}{ Predefine design parameters } \\
\hline $\begin{array}{l}\text { Turbine } \\
\text { output } \\
\text { power, } P \\
{[\mathrm{~W}]}\end{array}$ & $\begin{array}{l}\text { Fluid } \\
\text { density, } \rho \\
{\left[\mathrm{Kg} / \mathrm{m}^{3}\right]}\end{array}$ & $\begin{array}{l}\text { Water } \\
\text { velocity, } \\
V_{1}[\mathrm{~m} / \mathrm{s}]\end{array}$ & $\begin{array}{l}\text { Power } \\
\text { coefficient, } \\
C_{p}\end{array}$ & $\begin{array}{l}\text { Efficiency, } \\
\eta\end{array}$ & $\begin{array}{l}\text { Blade } \\
\text { Number, } \\
B\end{array}$ & $\begin{array}{l}\text { Lift } \\
\text { coefficient, } \\
C_{L}\end{array}$ & $\begin{array}{l}\text { Drag } \\
\text { coefficient, } \\
C_{D}\end{array}$ \\
\hline 746 & 997 & 1.5 & 0.4382 & 0.7 & 3 & 0.8 & 0.009 \\
\hline $\begin{array}{l}\text { Tip speed } \\
\text { ratio, } \lambda\end{array}$ & $\begin{array}{l}\text { Angle of } \\
\text { attack, } \alpha\end{array}$ & \multicolumn{3}{|c|}{ Axial induction factor, $a$ Eqn. (12) } & $\begin{array}{l}\text { Rotational } \\
\text { speed, } \omega \\
{[\mathrm{rad} / \mathrm{s}]} \\
\text { Eqn. (4) }\end{array}$ & $\begin{array}{l}\text { Rotor } \\
\text { radius, } R \\
\text { [m] Eqn. (1) }\end{array}$ & $\Delta r$ \\
\hline 6.325 & $5^{\circ}$ & 1.291 & 0.153 & 0.556 & 13.952 & 0.680 & 0.068 \\
\hline \multicolumn{8}{|c|}{ Computed parameters } \\
\hline $\begin{array}{l}\text { Station No. } \\
\text { (1 root, } 10 \\
\text { tip) }\end{array}$ & $\begin{array}{l}\text { Blade } \\
\text { element, } r \\
{[\mathrm{~m}]}\end{array}$ & $\begin{array}{l}\text { Local tip } \\
\text { speed } \\
\text { ratio, } \lambda_{r} \\
\text { Eqn. (8) }\end{array}$ & $\begin{array}{l}\text { Angular } \\
\text { induction } \\
\text { factor, } a ́\end{array}$ & $\begin{array}{l}\text { Relative } \\
\text { velocity } \\
\text { angle, } \phi \\
\text { (rad) Eqn. } \\
\text { (7) }\end{array}$ & $\begin{array}{l}\text { Relative } \\
\text { velocity } \\
\text { angle, } \phi \\
\text { (deg) }\end{array}$ & $\begin{array}{l}\text { Blade twist, } \\
\beta \text { Eqn.(6) }\end{array}$ & $\begin{array}{l}\text { Chord } \\
\text { length, } C \\
\text { [m] Eqn. (5) }\end{array}$ \\
\hline 1 & 0.068 & 0.633 & 0.257 & 0.817 & 46.83 & 41.83 & 0.101 \\
\hline 2 & 0.136 & 1.265 & 0.075 & 0.557 & 31.93 & 26.93 & 0.086 \\
\hline 3 & 0.204 & 1.898 & 0.035 & 0.407 & 23.35 & 18.35 & 0.068 \\
\hline 4 & 0.272 & 2.530 & 0.020 & 0.317 & 18.18 & 13.18 & 0.054 \\
\hline 5 & 0.340 & 3.163 & 0.013 & 0.259 & 14.18 & 9.82 & 0.045 \\
\hline 6 & 0.408 & 3.795 & 0.009 & 0.218 & 12.48 & 7.48 & 0.039 \\
\hline 7 & 0.476 & 4.428 & 0.007 & 0.188 & 10.77 & 5.77 & 0.0034 \\
\hline 8 & 0.544 & 5.060 & 0.005 & 0.165 & 9.46 & 4.46 & 0.0030 \\
\hline 9 & 0.612 & 5.693 & 0.004 & 0.147 & 8.43 & 3.43 & 0.027 \\
\hline 10 & 0.680 & 6.325 & 0.003 & 0.133 & 7.61 & 2.61 & 0.025 \\
\hline
\end{tabular}

After founding the value of $C$ for every section, the next step was to multiply these values by the non-dimensional coordinates of the S822. The values of $x$ and $y$ coordinates of the profile for each section were exported to parametric 3D design software. Therefore, the cross section of the blade were created at different 
sections from root to tip, and using the Loft command, a 3D model of the whole blade could be produced.

\section{Numerical simulation of a horizontal axis hydrokinetic turbine}

\subsection{CFD analysis}

After generating the hlade oenmetry the next sten ennsisted of determining the suitable geometry was obtained by $r$ incompressible flc geometries using $\mathrm{t}$ model. SolidWork in ANSYS, triang the complex geor independence of $\mathrm{t}$ ]

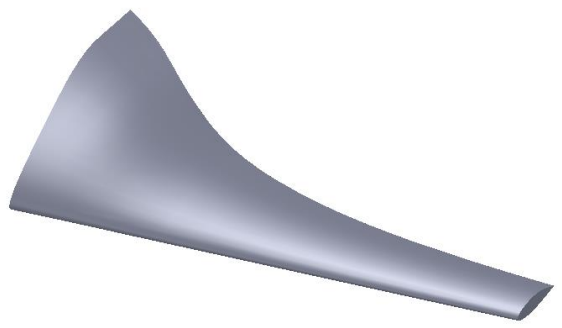
If the performance s a steady, and an $\mathrm{d}$ out for 3D flow e $k-\varepsilon$ turbulence enerating the grid ructured mesh for o ensure the grid through the increa btaining solutions the solutions exhibited negligible change with further increase in the number of nodes. Consequently, the grid size giving the grid-independent results were selected and the total number of cells was chosen to be $10,529,801$ nodes. The external domain was a rectangular parallelepiped of width of $8 R$, length of $15 R$ and height of $5 R$ in transverse, the streamwise and vertical directions, respectively. The internal rotation area was a cylinder with a diameter of $2.3 R$. The turbine blade had S822 hydrofoil section and was placed inside the inner cylinder. The computational domain and the coordinates are shown in fig. 3 .

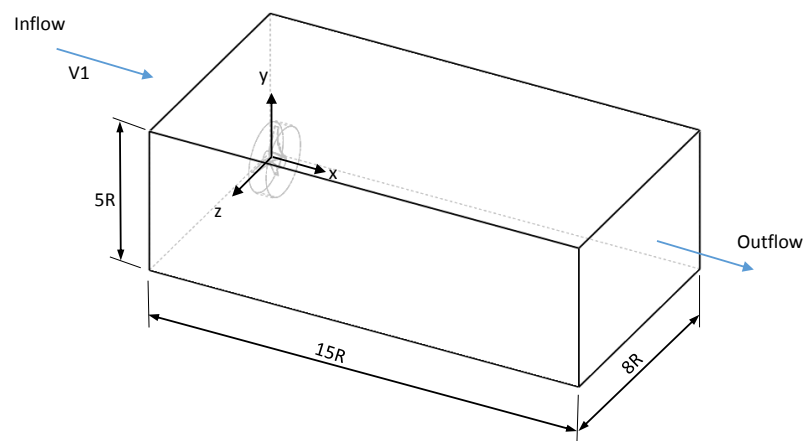

Figure 3: Computational domain. The flow direction is from $-\mathrm{x}$ to $+\mathrm{x}$.

In the computational domain entrance, a uniform velocity profile equal to $1.5 \mathrm{~m} / \mathrm{s}$ was defined. The non-slip boundary conditions were used in the domain walls. At the domain output, the zero static pressure was applied. Additionally, a 
general frozen rotor interface connection between the rotational and the stationary domain was used.

From CFD analysis, the pressure distribution around the blade at its half length is presented in fig. 4a). The pressure on the lower surface of the airfoil was greater than that of the incoming flow stream. As a result, a trust upstream of the airfoil was generated. This difference in pressure across the blade pressure and suction sides mainly influences in the driving force to create torque to turn the turbine.
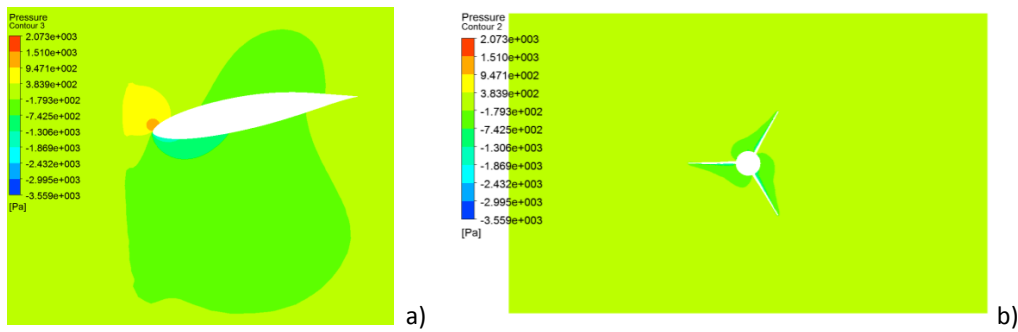

Figure 4: Distribution of pressure on the blade a) Plane parallel to the $X Y$ define by $Z=0.3 \mathrm{~m}$. b) Plane parallel to the $Y Z$ defined by $X=0 \mathrm{~m}$.

On the other hand, fig. 4b) shows the distribution of pressures on the blades in a plane parallel to the $Y Z$ defined by $X=0 \mathrm{~m}$. From this figure, maximum pressures values at the root blades are observed.

Fig. 5 shows the velocity field on the blade in a plane parallel to the $X Y$ defined by $Z=0.34 \mathrm{~m}$ (half the length of the blade). It can be observed that the upper airfoil surface experiences a higher velocity compared to the lower surface. Velocity contours around the airfoil show that maximum velocity $(2.745 \mathrm{~m} / \mathrm{s})$, with respect to the mean velocity of $1.5 \mathrm{~m} / \mathrm{s}$, appears around the leading edge.

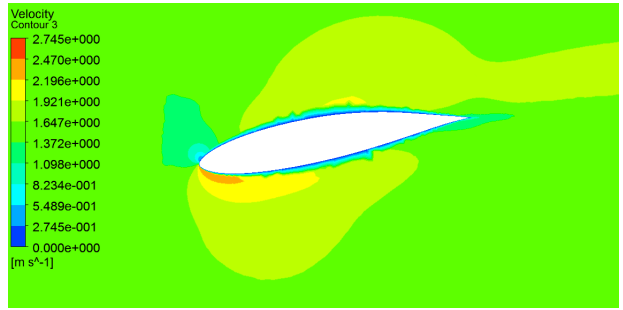

Figure 5: Distribution of velocities on the blade in a plane parallel to the $X Y$ defined by $Z=0.34 \mathrm{~m}$.

The simulation allows computing the torque on the blade $(18.5174 \mathrm{Nm})$, which is subsequently multiplied by the blade total number (3) and angular velocity $(13.952 \mathrm{rad} / \mathrm{s})$. Thus, the turbine power output was calculated $(775.06 \mathrm{~W})$. This 
value was compared to the design power $(746 \mathrm{~W})$. The good agreement between the numerical and theoretical turbine power output enables to validate the design of the rotor.

\subsection{FEM analysis}

As a part of the design process, the blades of a hydrokinetic turbine must be analyzed for aerodynamic, gravitational, inertial and operational loads experienced during their operating life. Therefore, and in order to know the global behavior of the blade in terms of the tip deflection and stress levels, the blade geometry was modelled in SolidWorks. The finite element model was also developed using this software through the stress analysis module. The blade consists of two faces or skins (suction and pressure side) and structural shear webs and several stations (fig. 6). The position, amount and shape of the shear webs are important in the blade behavior. The structure of the blade was modelled with shell elements using 72,838 nodes, 35,724 elements and $3 \mathrm{~mm}$ of thickness.

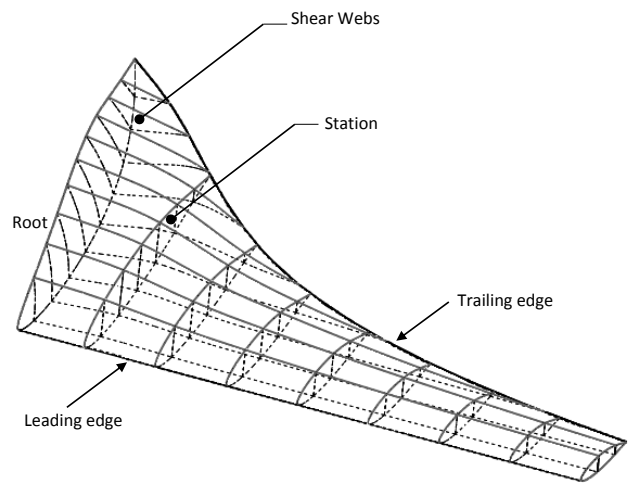

Figure 6: Structural model of the blade.

The blade was treated as a cantilevered beam with all the degrees of freedom fixed at the root. Centrifugal, gravitational and hydrodynamic forces were used for structural analysis. The hydrodynamic forces were calculated using eqns (10) and (11) for each section of the blade from $r_{1}$ to $r_{10}$. For simplicity, the load was reduced to several concentrated loads applied on each section of the blade from the pressure side towards the suction side.

A total load of $329.388 \mathrm{~N}$ and $72.492 \mathrm{~N}$ was modeled in the normal and tangential direction, respectively. The centrifugal load was located at the rotation center of the rotor (axial velocity of $13.952 \mathrm{rad} / \mathrm{s}$ ). The von-Mises stress and displacements were calculated for different material combinations. The mechanical properties of the blade parts are presented in Table 2. The materials chosen for the design of the blade are low cost and available in developing countries. 
Table 2: Mechanical properties of the blade [7,8].

\begin{tabular}{|l|l|l|l|l|l|}
\hline Part & Material & $\begin{array}{l}\text { Young's modulus } \\
(\mathrm{GPa})\end{array}$ & $\begin{array}{l}\text { Density } \\
\left(\mathrm{Kg} / \mathrm{m}^{3}\right)\end{array}$ & $\begin{array}{l}\text { Poisson's } \\
\text { ratio }\end{array}$ & $\begin{array}{l}\text { Tensile } \\
\text { Strength, } \\
\text { Ultimate/ } \\
\text { Yield } \\
(\mathrm{MPa})\end{array}$ \\
\hline $\begin{array}{l}\text { Skins (suction and } \\
\text { pressure side) }\end{array}$ & Glass fiber (type E) & 72.3 & 2500 & 0.276 & 3445 \\
\cline { 2 - 6 } & Glass fiber epoxy & 20.4 & 2000 & 0.217 & 241 \\
\hline \multirow{2}{*}{$\begin{array}{l}\text { Shear webs and } \\
\text { stations }\end{array}$} & Pine wood (dry) & 10.07 & 500 & 0.292 & 49 \\
\cline { 2 - 7 } & $\begin{array}{l}\text { ABS (Acrylonitrile } \\
\text { Butadienes Styrene) }\end{array}$ & 2.41 & 1070 & 0.394 & 34.96 \\
\cline { 2 - 7 } & Aluminum (6061-T6) & 69 & 2700 & 0.33 & $310 / 276$ \\
\hline
\end{tabular}

Table 3: Structural simulation results of the blade.



Six models were created from the combination of two skin materials and three materials for the shear webs and stations. The results for maximum von-Mises stresses, over the complete geometry of the blade are presented in Table 3. None of the shown stresses in any region of the blade reached the limit values concerning the mechanical strength of the material for yielding. Stresses were maximum at the blade root for all models, except for 5 and 6 models, where the maximum stress was shown in the shear webs near the section $r_{8}$. The stress level was lower if 
the ratio between the modulus of elasticity of the materials by which the blade was manufactured was low. The maximum displacement occurred at the tip of the blade and is lower in model 1 and 5 .

Finally, in the design process of the blade, it is essential to choose a simplified method construction allowing making the blade locally in rural communities or near them for reducing turbine total costs. Technically, the turbine can be fabricated by a wide range of methods, ranging from hand carving up to CNC machine. It can be fabricated using wood as the core and applying external layups of glass fiber (type E) or glass fiber epoxy [6,7].

\section{Conclusion}

In this work, a horizontal axis hydrokinetic turbine blade is designed and verified with the help of the momentum theory, the blade element momentum theory and numerical simulation. The optimum twist angle and chord length for each section of the blade were calculated using turbine output power, tip speed, aerofoil, water speed and efficiency, among others, as design parameters

The finite element analysis indicates that the blade will satisfactorily support the force exerted on it under the combined effects of the centrifugal, gravitational and hydrodynamic loads studied here. On the other hand, there is a good comparison between the turbine design power and the obtained power from the numerical simulation using a CFD model of the turbine.

\section{References}

[1] Anyi, M. and Kirke, B., Evaluation of small axial flow hydrokinetic turbines for remote communities. Energy for Sustainable Development, 14(2), pp. 110 $116,2010$.

[2] Vermaak, H.J., Kusakana, K. and Koko, S.P., Status of micro-hydrokinetic river technology in rural applications: A review of literature. Renewable and Sustainable Energy Reviews, 29(0), pp. 625-633, 2014.

[3] Khan, M., Bhuyan, G., Iqbal, M. and Quaicoe, J., Hydrokinetic energy conversion systems and assessment of horizontal and vertical axis turbines for river and tidal applications: A technology status review. Applied Energy, 86(10), pp. 1823-1835, 2009.

[4] Slootweg, J., Polinder, H. and Kling, W., Dynamic modelling of a wind turbine with doubly fed induction generator. Power Engineering Society Summer Meeting, 2001, volume 1, pp. 644-649, 2001.

[5] Manwell, J.F., McGowan, J.G. and Rogers, A.L., Wind energy explained: theory, design and application. Wiley: Chichester, 2009.

[6] Hydrokinetic turbine blades: Design and local construction techniques for remote communities. Energy for Sustainable Development, 15(3), pp. 223230,2011 . Special issue on off-grid electrification in developing countries. 
148 Energy and Sustainability VI

[7] Munoz, A., Chiang, L. and la Jara, E.D., A design tool and fabrication guidelines for small low cost horizontal axis hydrokinetic turbines. Energy for Sustainable Development, 22(0), pp. 21-33, 2014. Wind Power Special Issue.

[8] Material property data. http://www.matweb.com, 2015. 